\title{
Medical Management of Acute Liver Failure
}

\author{
Heli Bhatt and Girish S. Rao
}

\section{Introduction and Definition}

Acute liver failure (ALF) is among the very few dramatically devastating illnesses in medicine. It is a rare disorder characterized by rapid-onset severe hepatocellular injury and dysfunction which can quickly progress to multisystem organ failure and death. It is characterized by signs of severe liver function abnormalities including jaundice, coagulopathy, and/or hepatic encephalopathy within a few weeks of onset of the disease. In adults, ALF is defined as onset of hepatic encephalopathy within 8 weeks of signs of hepatic dysfunction, i.e., jaundice and coagulopathy [1]. This definition of ALF in adults cannot be applied directly to children because it is difficult to accurately assess age-appropriate mental status and exact duration of illness in children. Also, hepatic encephalopathy may not be clinically apparent until terminal stages of liver failure in children [2]. This makes diagnosis of acute liver failure especially challenging in children [3, 4].

The Pediatric Acute Liver Failure (PALF) study group is a multisite, multinational consortium established in 1999 to prospectively study ALF in children [3, 5]. This study group defines PALF as biochemical/laboratory evidence of

H. Bhatt · G. S. Rao $(\bowtie)$

Riley Hospital for Children at Indiana University Health, Division of Pediatric Gastroenterology, Hepatology, and Nutrition, Indianapolis, IN, USA e-mail: gsrao@iu.edu liver injury in a child with no known evidence of chronic liver disease and:

(a) Prothrombin time (PT) $\geq 15 \mathrm{~s}$ or international normalized ratio (INR) $\geq 1.5$ not corrected by vitamin $\mathrm{K}$ administration in presence of hepatic encephalopathy (HE)

(b) PT $\geq 20$ s or INR $\geq 1.5$ not corrected by vita$\min \mathrm{K}$ administration irrespective of the presence or absence of hepatic encephalopathy [3]

The exact incidence of PALF is unknown; however, PALF accounts for about $10-15 \%$ of pediatric liver transplants performed in the USA annually [6]. A specific diagnosis is not available for almost half of these patients [3]. The data for outcome of this devastating illness is limited. The recent data regarding patient outcome from the PALF study group demonstrated that age less than 3 years, indeterminate or non-acetaminophen-induced liver failure, higher grades of encephalopathy, bilirubin $\geq 5 \mathrm{mg} / \mathrm{dL}$, and INR $\geq 2.55$ on admission are all associated with worse outcomes [3].

\section{Etiology}

The etiology of ALF in children varies between infants versus older children [7]. The most common overall cause of PALF is indeterminate. 
Up to $40-50 \%$ patients with PALF lack a specific etiological diagnosis partly due to lack of thorough diagnostic evaluation [8]. In infants, infections and metabolic diseases are the most common known etiologies for PALF [7, 8]. Herpes simplex virus is the most commonly identified infectious etiology in these children. Galactosemia, tyrosinemia, and fatty acid oxidation defect are the commonly identified metabolic disorders in this age group, while neonatal hemochromatosis was the most common cause of liver failure in the neonatal period [7]. In children older than 7 months of age with ALF, drug toxicity, especially with acetaminophen overdose, and autoimmune hepatitis are the most commonly identified etiologies [7, 8]. In developing countries, infectious etiologies remain the most common identified cause of acute liver failure through all age groups. Hepatitis A viral infection is the most common infectious agent in these countries [8].

\section{Diagnostic Evaluation}

All children with ALF should undergo thorough systematic evaluation for the underlying etiology of acute liver failure along with the assessment for liver injury, dysfunction, and multisystem complications. This diagnostic evaluation should be individualized and directed toward the age-specific causes of acute liver failure. A detailed medical history including onset of symptoms and neurological changes; history of exposure to infections or medications; family medical history including history of liver disease, consanguinity, genetic, metabolic, or autoimmune diseases; and/or sibling death should be obtained in all patients with acute liver failure. A thorough physical examination with special attention to mentation and neurological status is imperative.

Radiological and laboratory tests in PALF should be obtained to evaluate underlying etiology, to assess the extent of liver injury and failure, or to monitor for potential complications of liver failure. A comprehensive metabolic panel including electrolytes, blood urea nitrogen (BUN), creatinine (Cr), and albumin, liver enzymes, total and fractionated bilirubin, gamma-glutamyl transferase (GGT), coagulation profile along with prothrombin time (PT) with international normalized ratio (INR), a complete blood count with differential and platelets, and a reliable serum ammonia level should be obtained in all the patients at diagnosis and thereafter monitored closely. Additional tests to assess for etiology of liver failure should be tailored to the age and presentation of the illness. These should be targeted to evaluate for infectious, metabolic, and autoimmune liver diseases in addition to drug or other toxin exposures (Table 9.1) [9]. A complete abdominal ultrasound with Doppler should be obtained in all patients with PALF, but additional imaging studies like CT, MRI, and/or MRCP should be considered based on the individual case. Liver biopsy should be considered early in the course of PALF to assess for the cause of liver failure and the extent and pattern of hepatocyte injury. Transjugular approach is preferred in the setting of severe coagulopathy with liver failure. The level of necrosis might be underestimated on liver biopsy [10]. Submassive or massive liver necrosis is associated with poor prognosis [11].

\section{Management}

Management of acute liver failure is very challenging due to multiple reasons. The multisystem organ involvement with potential for rapid deterioration and death in absence of timely liver transplant makes this disease one of the most difficult diseases to manage. At the same time, there is a tremendous potential for self-recovery without transplant and unnecessary morbidity can be avoided by preventing transplants in these cases. There is a lack of adequate data on management of PALF due to its rarity and currently, the majority of our clinical practice guidance is derived from adult studies. Hence, many principles of management of this disease are currently unclear and controversial. 
Table 9.1 Diagnostic evaluation [85]

\begin{tabular}{l|l}
\hline Age-based causes & Diagnostic evaluation \\
\hline Idiopathic or indeterminate (all ages) & $\begin{array}{l}\text { Liver function tests: AST, ALT, GGT, alkaline } \\
\text { phosphatase, fractionated bilirubin, albumin, total protein }\end{array}$ \\
Coagulation: PT-INR, aPTT, fibrinogen, factors V, VII, \\
VIII \\
Ammonia level, blood gas, CBC with PLT, and \\
differential \\
Complete metabolic panel: electrolytes, BUN, creatinine, \\
blood glucose, Ca, Mg, P \\
Imaging studies: ultrasound liver with Doppler study \\
Tissue diagnosis: liver biopsy; muscle biopsy as indicated
\end{tabular}

Infectious:

1. Infancy: HSV 1 and 2 - most common, enterovirus, adenovirus, hepatitis $\mathrm{B}$, hepatitis $\mathrm{C}, \mathrm{EBV}, \mathrm{CMV}$, HHV 6, parvovirus

2. Preadolescence: hepatitis A, B, C, D, E, non-A and non-B viral hepatitis, EBV, CMV, enterovirus, adenovirus, HHV-6, parvovirus

3. Adolescents: hepatitis A, B, C, D, E, non-A and non-B viral hepatitis, EBV, CMV

Metabolic:

1. Infancy: fatty acid defects, mitochondrial defects, galactosemia, tyrosinemia, etc.

2. Preadolescence: Wilson's disease, fatty acid oxidation defects, mitochondrial defects, etc.

3. Adolescents: Wilson's disease, etc.

Viral PCR for EBV, CMV, enterovirus, adenovirus,

HHV-6, HSV 1 and 2, parvovirus

Viral hepatitis serology including anti-HAV Ig M,

HBsAg, anti-HBe Ig M and Ig G, anti-HCV, and anti-HEV

Immune dysregulation:

1. Infancy: neonatal hemochromatosis

2. Preadolescence/adolescence: autoimmune hepatitis, HLH

Serum lactate, pyruvate, amino acid profile, carnitine profile, acyl-carnitine profile

Urine amino acid/organic acid profile, urine

succinylacetone, serum ceruloplasmin, and 24-h urine copper

Ferritin, iron, TIBC

Antinuclear antibody, anti-smooth muscle antibody, anti-liver-kidney-microsome antibody, Ig G level, anti-soluble liver antigen/anti-liver pancreas antibody, anti-liver cytosol type I antigen

Drug toxicity or accidental ingestion:

1. Infancy: acetaminophen, acetylsalicylic acid, valproic acid, etc.

2. Adolescence: acetaminophen, tetracycline, ecstasy, toxic mushroom Amanita phalloides poisoning, etc.

$H S V$ herpes simplex virus, $E B V$ Epstein-Barr virus, $C M V$ cytomegalovirus, $H H V-6$ human herpesvirus 6 , AST aspartate aminotransferase, ALT alanine aminotransferase, GGT gamma-glutamyl transferase, PT-INR prothrombin time and international normalized ratio, $a P T T$ activated partial thromboplastin time, $P C R$ polymerase chain reaction, $H A V$ hepatitis A virus, $H B s A g$ hepatitis B surface antigen, $H C V$ hepatitis $\mathrm{C}$ Virus, $H E V$ hepatitis E virus, $T I B C$ total iron-binding capacity, $H L H$ hemophagocytic lymphohistiocytosis

\section{General Principles of Management}

Pediatric patients with acute liver failure are best managed in intensive care units (ICU) by a multidisciplinary medical team. Intensive care units play a pivotal role by close monitoring and supporting of failing organs as well as providing clinical stability for multiple lifesaving interventions. Advances in critical care have contributed significantly toward decreasing mortality in adult ALF patients [12]. We can safely assume that similar advances in pediatric critical care will definitely improve outcomes in PALF.

Patients with PALF demonstrating signs of altered mental status and/or worsening coagulopathy should be closely monitored in the ICU with frequent neurological and cardiorespiratory assessments. After initial 
characterization of presentation and stabilization of the patient, further management should be focused on monitoring and supporting the patient and organ systems, identifying and treating complications (Table 9.2), employing targeted diagnostic evaluation, and optimizing outcomes [5].
Close collaboration between pediatric intensivist, pediatric hepatologist, transplant surgeons, neurologist, nephrologist, and metabolic/genetic disease specialist is crucial to provide the best outcome for the patient. Early transfer to a transplant center should be of utmost importance to facilitate the multidisciplinary approach and

Table 9.2 Management of complications in PALF [85]

\begin{tabular}{|c|c|c|}
\hline Organ system & Complications & Management of complications \\
\hline $\begin{array}{l}\text { Central nervous } \\
\text { system }\end{array}$ & $\begin{array}{l}\text { Hepatic encephalopathy } \\
\text { Cerebral edema } \\
\text { Intracranial hypertension }\end{array}$ & $\begin{array}{l}\text { Supportive care in ICU, minimal stimulation } \\
\text { Endotracheal intubation for grade } 3 \text { or } 4 \\
\text { encephalopathy } \\
\text { Consider CT/MRI head for any acute mental status } \\
\text { changes } \\
\text { Prophylactic HTS (3-30\%) or mannitol } 0.25-1.0 \\
\text { gm/kg IV bolus, repeated once or twice }\end{array}$ \\
\hline Cardiovascular & $\begin{array}{l}\text { Systemic hypotension due to } \\
\text { intravascular volume depletion } \\
\text { Hyperdynamic circulatory failure }\end{array}$ & $\begin{array}{l}\text { Adequate fluid resuscitation with IV crystalloids } \\
\text { Norepinephrine for volume-refractory hypotension } \\
\text { Consider vasopressin and its analogs }\end{array}$ \\
\hline Adrenal & $\begin{array}{l}\text { Relative adrenal insufficiency (RAI) } \\
\text { Hepatoadrenal syndrome }\end{array}$ & $\begin{array}{l}\text { Consider a trial of systemic steroids in patients with } \\
\text { persistent vasopressor, fluid refractory shock }\end{array}$ \\
\hline Respiratory & $\begin{array}{l}\text { Acute respiratory failure } \\
\text { Pulmonary edema } \\
\text { Pulmonary hemorrhage } \\
\text { Acute respiratory distress syndrome } \\
\text { (ARDS) }\end{array}$ & $\begin{array}{l}\text { Endotracheal intubation for respiratory failure or } \\
\text { airway protection in advanced stages of hepatic } \\
\text { encephalopathy } \\
\text { Ventilator strategies: low tidal volumes ( } 5-8 \mathrm{ml} / \mathrm{kg} \\
\text { of predicted weight) and moderately elevated PEEP } \\
\text { levels; avoid sustained hyperventilation }\end{array}$ \\
\hline Renal & $\begin{array}{l}\text { Acute kidney injury (AKI) } \\
\text { Hepatorenal syndrome }\end{array}$ & $\begin{array}{l}\text { Preventive measures: maintain fluid balance, } \\
\text { minimize nephrotoxic medications or IV contrast } \\
\text { CRRT is preferred }\end{array}$ \\
\hline $\begin{array}{l}\text { Fluid, electrolytes, } \\
\text { and nutrition }\end{array}$ & $\begin{array}{l}\text { Hypoglycemia } \\
\text { Hyperammonemia } \\
\text { Intravascular volume depletion } \\
\text { Alkalosis and acidosis } \\
\text { Electrolyte abnormalities } \\
\text { Catabolic state with negative nitrogen } \\
\text { balance and increased energy } \\
\text { expenditure }\end{array}$ & $\begin{array}{l}\text { Continuous glucose infusion to maintain } \\
\text { euglycemia } \\
\text { Consider CRRT } \\
\text { Frequent monitoring and correction of electrolytes } \\
\text { and acid-base balance } \\
\text { Avoid hyponatremia to prevent cerebral edema } \\
\text { Enteral nutrition with high caloric density formula } \\
\text { to avoid excess free water } \\
\text { Parenteral nutrition: a safe second-line choice in } \\
\text { patients who cannot be fed enterally }\end{array}$ \\
\hline Hematological & $\begin{array}{l}\text { Coagulopathy not corrected by } \\
\text { vitamin K administration } \\
\text { Disseminated intravascular } \\
\text { coagulopathy }\end{array}$ & $\begin{array}{l}\text { Plasma or platelet transfusions only recommended } \\
\text { prior to invasive procedure or during active } \\
\text { bleeding } \\
\text { Vitamin K administration is recommended }\end{array}$ \\
\hline Gastrointestinal & $\begin{array}{l}\text { Gastrointestinal bleeding } \\
\text { Ascites }\end{array}$ & $\begin{array}{l}\mathrm{H} 2 \text { blocker or proton pump inhibitors for } \\
\text { prophylaxis of gastrointestinal bleed } \\
\text { Spironolactone for diuresis in patients with ascites } \\
\text { who have respiratory compromise or discomfort }\end{array}$ \\
\hline Infectious & $\begin{array}{l}\text { Systemic inflammatory response } \\
\text { syndrome } \\
\text { Bacterial infections such as } \\
\text { staphylococci, streptococci, and } \\
\text { enteric gram-negative bacteria }\end{array}$ & $\begin{array}{l}\text { Aggressive surveillance with cultures and empiric } \\
\text { antibiotics in the presence of SIRS, worsening } \\
\text { encephalopathy, refractory hypotension } \\
\text { No role for prophylactic antimicrobials }\end{array}$ \\
\hline
\end{tabular}

HTS hypertonic saline, CRRT continuous renal replacement therapy, SIRS systemic inflammatory response syndrome 
timely decision-making for critical aspects of patient care and interventions including transplantation and its evaluation.

\section{Central Nervous System}

Hepatic encephalopathy (HE) is a neuropsychiatric syndrome associated with liver failure in the absence of a preexisting brain disease. It is characterized by progressive but reversible deterioration of behavior, cognition, and mentation in patients with PALF. The clinical features of hepatic encephalopathy can range from overt coma to irritability to minor changes in behavior and motor or cognitive skills. In children, features of HE can be subtle and difficult to assess and range from mild irritability to inactivity to coma. Table 9.3 describes the clinical stages of encephalopathy originally developed to assess patients with cirrhosis but is used in ALF for the lack of a better clinical tool. In the Pediatric Acute Liver Failure study group database, the majority of the patients (75\%) had grade 1-2 hepatic encephalopathy, and grade 3 and 4 encephalopathy were seen in $17 \%$ and $7 \%$ patients, respectively. Out of 348 patients included in this study group, more than half developed hepatic encephalopathy [3].

The exact pathogenesis of hepatic encephalopathy is complex, is not completely understood, and involves a number of interrelated factors [4, 13]. Ammonia is a by-product of nitrogen metab- olism that is generated from the breakdown of glutamine by glutaminase, an enzyme within the enterocytes of the small intestine and colon, and by urease-producing bacteria that inhabit the gut. This gut-derived ammonia enters the urea cycle to be detoxified into urea and excreted in the urine. Ammonia that bypasses this detoxification is converted to glutamine in hepatocytes, skeletal myocytes, and astrocytes in brain. Astrocytes are the most abundant type of cells in the brain. They are very sensitive to a rapid increase in ammonia, which subsequently leads to cellular edema due to increased influx of water secondary to osmotic gradient created by increased intracellular glutamine. Although hyperammonemia has been implicated to play a pivotal role in development of hepatic encephalopathy, a consistent correlation between the plasma concentration of ammonia and clinical manifestation of HE has not been established [14]. In addition to hyperammonemia, increased proinflammatory circulatory cytokines like IL- $1 \beta$, IL- 6 , and TNF- $\alpha$ can modulate cerebral blood flow and cellular permeability to have direct or permissive effects on development and progression of HE into cerebral edema [15].

\section{Management of Hepatic Encephalopathy}

Given the potential for rapid neurological deterioration in patients with PALF and HE, early recognition and prompt management of $\mathrm{HE}$ are

Table 9.3 Stage of encephalopathy $[4,5]$

\begin{tabular}{l|l|l|l|l}
\hline Grade & Symptoms & Signs & Reflexes & EEG \\
\hline $\begin{array}{l}\text { Grade } \\
0\end{array}$ & Normal & None & Normal & Normal \\
\hline $\begin{array}{l}\text { Grade } \\
1\end{array}$ & $\begin{array}{l}\text { Inconsolable crying, } \\
\text { confused, not acting like self }\end{array}$ & $\begin{array}{l}\text { Difficult to } \\
\text { examine }\end{array}$ & $\begin{array}{l}\text { Difficult to examine; normal } \\
\text { or hyperreflexic if able to } \\
\text { examine }\end{array}$ & Difficult to obtain \\
\hline $\begin{array}{l}\text { Grade } \\
2\end{array}$ & $\begin{array}{l}\text { Inconsolable crying, } \\
\text { drowsiness, not acting like } \\
\text { self }\end{array}$ & $\begin{array}{l}\text { Difficult to } \\
\text { examine }\end{array}$ & Normal or hyperreflexic & Difficult to obtain \\
\hline $\begin{array}{l}\text { Grade } \\
3\end{array}$ & $\begin{array}{l}\text { Combativeness, increasing } \\
\text { somnolence, stupor }\end{array}$ & Rigidity & $\begin{array}{l}\text { Hyperreflexic, positive } \\
\text { Babinski sign }\end{array}$ & $\begin{array}{l}\text { Generalized } \\
\text { slowing }\end{array}$ \\
\hline $\begin{array}{l}\text { Grade } \\
4\end{array}$ & $\begin{array}{l}\text { Comatose, may or may not } \\
\text { arouse with painful stimuli }\end{array}$ & $\begin{array}{l}\text { Decerebrate or } \\
\text { decorticate } \\
\text { posturing }\end{array}$ & Absent & $\begin{array}{l}\text { Abnormal, very } \\
\text { slow, delta activity }\end{array}$ \\
\hline
\end{tabular}


necessary to decrease morbidity and mortality in these patients. As mentioned above, these patients should be closely monitored in a critical care setting with frequent neurological assessments. There should be minimal stimulation, and unnecessary interventions should be avoided. Endotracheal intubation for airway protection or controlled ventilation in advanced stages of encephalopathy should be considered. Head of the bed should be elevated to $20-30^{\circ}$, and the patient's head should be maintained in the midline to provide optimal CSF drainage and jugular venous outflow. Aggressive efforts to maintain normothermia are crucial as fever and shivering may exacerbate intracranial pressure (ICP). Ventilation, oxygenation, and mean arterial pressures should be meticulously monitored and maintained.

Lactulose and nonabsorbable oral antibiotics like neomycin and rifaximin have been used for prophylaxis and management of $\mathrm{HE}$ in patients with chronic liver disease and cirrhosis. Lactulose is a synthetic nonabsorbable disaccharide which can be used to decrease intraluminal $\mathrm{pH}$ in the colon and prevent uptake of ammonia from the gastrointestinal lumen. Given the central role of increased arterial ammonia levels in the pathogenesis of hepatic encephalopathy, one could assume that ammonia-lowering strategies might be effective in halting the progression of neurological deterioration. While the abovementioned agents have a role in preventing progression of $\mathrm{HE}$ associated with cirrhosis in patients with chronic liver disease, there are no controlled trials to support the use of these medications to treat hepatic encephalopathy in ALF [16-18]. In one nonrandomized retrospective series, there was no improvement in outcome with lactulose therapy [19]. Lactulose use should be avoided in PALF as it has the potential to cause intravascular volume depletion, hypernatremia, and bowel distension or megacolon, which can be dangerous during transplant $[16,17]$. Neomycin is also not recommended due to increased risk of nephrotoxicity [16]. L-Ornithine L-aspartate (LOLA) and L-ornithine phenyl acetate (LOPA) have shown promising results in adult trials [20]. These work by increasing renal excretion of ammonia.
Currently, there is no data to support their use in PALF. The benefit of continuous renal replacement therapy (CRRT) in reducing serum ammonia and improving 21-day transplant-free survival has been demonstrated in a recent cohort study from US ALF study group registry [21].

\section{Management of Intracranial Hypertension and Cerebral Edema}

The goal in the management of cerebral edema and intracranial hypertension is maintaining adequate cerebral perfusion pressure (CPP) while lowering and maintaining intracranial pressure (ICP) to less than $20 \mathrm{~mm} \mathrm{Hg}$ to assure adequate perfusion of the brain [4, 22]. Close clinical monitoring is strongly recommended but highly challenging in pediatric patients, especially if they have progressed to grade 3-4 HE. Cushing's triad of irregular breathing, systemic hypertension, and bradycardia is not uniformly present. Intracranial pressure monitoring can be used to assess CPP to avoid hypoxic brain injury. Multiple studies have been done to evaluate the safety and efficacy of invasive intracranial pressure monitoring in management of ALF, but there has been no demonstrated improvement in survival [23-25]. The use of invasive intracranial monitoring in PALF is controversial owing to the lack of sufficient evidence for its routine use and safety. Maintaining systemic blood pressure by adequate volume resuscitation and use of vasoactive medications as well as aggressively treating fluid overload with CRRT are crucial to maintain adequate CPP.

The principal therapy to reduce cerebral edema and increased intracranial pressure is administration of osmotic agents like hypertonic saline and mannitol [26]. Mannitol is a hyperosmolar agent, which works by promoting movement of water from astrocytes into the serum by increasing osmolality of serum. Mannitol also decreases viscosity of blood causing vasoconstriction, which leads to less cerebral blood volume and decreased ICP. It is used as a first-line agent in management of increased ICP in adults with ALF $[16,17]$. The recommended dose for 
use is $0.25-1.0 \mathrm{gm} / \mathrm{kg}$ IV bolus that can be repeated once or twice $[16,17]$. The majority of information on mannitol in PALF is extrapolated from adult literature. The effect of mannitol is transient, and it is difficult to achieve sustained reduction of ICP to acceptable levels with mannitol alone. The use of mannitol is not recommended in presence of renal failure, hypovolemia, or serum osmolality $>320 \mathrm{mOsm} / \mathrm{L}[16,17]$.

Hypertonic saline (3-30\%) decreases ICP by mechanisms similar to mannitol. In addition, it also stabilizes cerebral endothelial cell volume and improves cerebral circulation. In a randomized controlled trial from King's College, patients who received hypertonic saline had decreased ICP from baseline in the first $24 \mathrm{~h}$, and the incidence of ICP $>25 \mathrm{~mm} \mathrm{Hg}$ or greater was significantly lower than control group; however, it did not show improved survival in patients treated with HTS [27]. The use of hypertonic saline in treatment of elevated ICP in PALF has not been studied. In patients with PALF who have elevated ICP, it is reasonable to maintain serum sodium level around $145-150 \mathrm{mmol} / \mathrm{L}$, especially now that hypertonic saline has been established as a standard of care in management of pediatric patients with traumatic brain injury [28]. There are no randomized clinical trials regarding the use of hypertonic saline or mannitol in children. Hypertonic saline provides all benefits of hyperosmolar agent without the hemodynamic side effects associated with mannitol. According to 2012 guidelines for the medical management of severe traumatic brain injury in children, use of hypertonic saline is favored over the use of mannitol for management of ICH [29].

Patients with ALF hyperventilate due to the metabolic milieu associated with ALF, and this, in turn, helps restore cerebral autoregulation, vasoconstriction, and reduction of ICP. Effects of hyperventilation are temporary and continuous hyperventilation offers no survival benefit in patients with ALF [30]. Moreover, it has the potential to worsen cerebral edema due to cerebral hypoperfusion. According to American Association for the Study of Liver Disease (AASLD) position paper for management of ALF, hyperventilation may be used to manage acute life-threatening mannitol-refractory worsening of intracranial pressure to delay impending cerebral herniation, but sustained hyperventilation should be avoided in patients with ALF.

Hypothermia prevents cerebral edema by decreasing cerebral metabolism, neuronal inflammation, and oxidative stress. It also decreases ammonia level and improves cerebral hemodynamics. Therapeutic hypothermia to $32-35^{\circ}$ has been used in adults with ALF to reduce ICP for successfully bridging these patients to liver transplantation. There have been a few reports of beneficial effects of therapeutic hypothermia in adult patients with ALF [31, 32]. However, there have been complications reported with therapeutic hypothermia too. These include cardiac dysrhythmias, increased risk of infection, coagulopathy, electrolyte disturbances, hyperglycemia, and theoretical decreased hepatic regeneration [31, 32]. A multicenter retrospective cohort analysis of 97 patients enrolled in the US ALF study group did not find a difference in 21-day mortality as well as transplant-free survival with or without the use of therapeutic hypothermia [33]. There is no data to support the use of therapeutic hypothermia for neuroprotection. However, hyperthermia should be aggressively managed to avoid worsening of ICP. Currently, active normothermia $\left(36-37^{\circ}\right)$ remains the standard of care as it offers the best risk-benefit ratio [4].

Early identification of neurological decline and timely therapeutic interventions to minimize neurological morbidity are crucial in ALF because neurological morbidity is a major determinant of outcome in ALF [4]. However, clinical assessment of neurological status in pediatric patients can be difficult. Head imaging with computerized tomography (CT) scan is used to exclude intracranial hemorrhage as a cause of sudden decline in neurological status. However, in a recent single-center retrospective pediatric study assessing the role EEG in management of PALF by Hussain et al. [34], CT and magnetic resonance imaging (MRI), even though abnormal in $13 \%$ of patients, failed to demonstrate consistent abnormalities to suggest the presence of cerebral edema. There was no association between EEG and CT/MRI findings in this study. 
However, there was increased mortality in patients with certain EEG abnormalities. These included moderate to severe slowing, epileptiform discharge, and electrographic seizure. EEG seems to be a very sensitive tool to screen not only for subclinical seizures but also declining neurological status in patients progressing to grade 3 or 4 encephalopathy or with unexplained clinical deterioration [34, 35]. Transcranial Doppler ultrasonography has been shown to be helpful in measuring dynamic changes in ICP in a small retrospective study in adults with ALF [36]. There are no studies for this diagnostic modality in PALF.

Seizure activity worsens cerebral edema by increasing the oxygen requirement of the astrocytes [35]. The true frequency of seizures in patients with ALF may be underestimated without continuous EEG. In the study by Hussain et al. $11 \%$ of patients had clinical seizures; however, almost $5 \%$ of patients had subclinical nonconvulsive seizures [34]. Continuous EEG should be used in patients with grade 3 or $4 \mathrm{HE}$ or with acute decline in neurological status to rule out subclinical seizures $[4,35]$. Aggressive antiepileptic therapy should be implemented to control seizures to prevent further neurological morbidity. Phenytoin can be used for prompt control of epileptiform activity, and short-acting benzodiazepines can be used in phenytoin-refractory cases [17]. Valproic acid should be avoided if mitochondrial disease is suspected as the underlying etiology for ALF. Prophylactic phenytoin has been tried to suppress subclinical epileptiform activity in adults with ALF; however, a subsequent trial demonstrated no benefit of its use in preventing seizures, brain edema, or improving survival $[35,37]$. There are no pediatric trials to support the use of prophylactic phenytoin in management of PALF. Prophylactic phenytoin, therefore, cannot be recommended in PALF at this time. Although there are rare reports of druginduced liver injury with levetiracetam, it can be safely used in management of seizures in PALF.

Pain can arise from multiple diagnostic and therapeutic interventions and procedures in patients with PALF. Psychomotor agitation is known to increase ICP, and this may be espe- cially deleterious in advanced stages of hepatic encephalopathy. Pain management and sedation are important components of critical care management of children with ALF. Sedating nonintubated patients may be necessary, and anxiolytics should be used after carefully weighing the benefit of reducing agitation versus blunting the signs of neurological deterioration and exacerbating encephalopathy [4]. Also, numerous drugs used for sedation and analgesia have hepatic or renal clearance. There is a lack of sufficient data for the use of standard sedative or analgesic agents in PALF. Short-acting agents, with appropriate dose adjustments for liver dysfunction, should be used. Benzodiazepines can have prolonged sedative effect when used in patients with hepatic impairment and should be avoided. Furthermore, benzodiazepines and propofol have the potential to worsen HE by increasing gamma-aminobutyric acid (GABA) neurotransmission [38]. Propofol in limited doses and for short period of time may be used in older children without mitochondrial disease, due to shorter recovery time and neuroprotective effect through decreased cerebral blood flow and decrease in ICP [4, 39]. Opioid agents with short half-life such as fentanyl and remifentanil can be used concurrently to improve cardiovascular stability [16]. Dose adjustments are recommended while using dexmedetomidine for its sedative and analgesic effect in PALF as it is metabolized primarily in the liver [40]. Atracurium and cisatracurium are the preferred agents for neuromuscular blockade in PALF. These undergo ester hydrolysis and Hoffman elimination, and their duration of action in liver failure is similar to the same in normal liver function [41]. Vecuronium and rocuronium should be avoided in ALF as they undergo hepatic metabolism.

\section{Cardiovascular}

Hyperdynamic circulatory failure with low mean arterial pressure occurs in ALF due to peripheral vasodilation caused by elevated circulatory cytokines. This significantly decreases peripheral tissue oxygenation exacerbating multi-organ 
failure. Depleted intravascular volume due to decreased intake as well as increased transudation into extravascular space adds to this hemodynamic instability.

As with any patient with hypotension, intravascular volume status should be assessed and replenished with adequate volume replacement [17]. If the patient remains hypotensive after fluid resuscitation, vasopressors should be initiated to maintain mean arterial pressures within the ageappropriate normal range. This is crucial to assure adequate cerebral perfusion pressure. Norepinephrine has been the preferred agent in adults, mainly, because it provides a more consistent and predictable increase in cerebral perfusion while minimizing tachycardia and preserving splanchnic circulation [16]. Despite the lack of adequate pediatric data on choice of vasopressors, norepinephrine does seem to be a reasonable choice to optimize organ perfusion in PALF [4]. Vasopressin and its analogues can be used in volume- and norepinephrine-refractory cases to potentiate its effects; however, these should be used cautiously due to the potential direct cerebral vasodilatory effect that may worsen intracranial hypertension $[16,17]$. Echocardiography can be used to assess for systolic and diastolic dysfunction in patients not responding to volume and vasoactive support.

\section{Adrenal}

Although there is a discrepancy in the definition, relative adrenal insufficiency/hepatoadrenal syndrome has been well described in septic shock as well as ALF [42]. A third of adults with ALF may develop relative adrenal insufficiency, and its incidence seems to be directly proportional to the severity of liver failure [43]. Low HDL levels with increased circulatory endotoxins and proinflammatory markers like TNF- $\alpha$ lead to impaired cortisol secretion and impaired adrenal function that can depress sensitivity to catecholamines $[43,44]$. No data is available to define this condition in PALF or to guide diagnosis and management of relative adrenal insufficiency in PALF. However, children with PALF and vaso- pressor/fluid refractory hypotension may benefit from a trial of systemic corticosteroid administration $[16,45,46]$.

\section{Respiratory}

In adults, about $20-30 \%$ patients with ALF are diagnosed with acute respiratory distress syndrome (ARDS) [47]. Exact incidence of ARDS in PALF is unknown. According to the PALF study group data, almost $40 \%$ children with PALF required ventilator support [3]. Endotracheal intubation may be required in PALF either for airway protection in patients with hepatic encephalopathy or for management of respiratory failure secondary to sepsis, fluid overload-associated pulmonary edema, pulmonary hemorrhage, or ARDS.

There are no pediatric trials directing mechanical ventilation in children with PALF. Mechanical ventilation strategies in PALF should aim at decreasing ventilator associated lung injury while providing maximum neuroprotection in the setting of elevated intracranial pressure. Conservative tidal volume ventilation $(5-8 \mathrm{ml} / \mathrm{kg}$ of predicted body weight) with moderately elevated positive end expiratory pressures should be titrated to maintain normocapnia and avoid hypoxemia [48]. As mentioned above, sustained hyperventilation should be avoided as the effects of hyperventilation on intracranial pressure are temporary, and there is a potential risk of worsening cerebral edema by causing cerebral hypoxia [17]; however, it may be used briefly in sudden life-threatening worsening of intracranial pressure that is refractory to osmotic agents to delay impending cerebral herniation.

\section{Renal}

Acute kidney injury (AKI), and subsequent renal failure, is a relatively common complication of ALF. In large retrospective review using patients in the US Acute Liver Failure study group (ALFSG), AKI was seen in almost $47 \%$ patients with ALF [49]. In this study, there was decreased 
overall survival in patients with AKI versus patients without AKI. Also, there was decreased transplant-free survival in patients needing renal replacement therapy (RRT) or with advanced AKI versus those without AKI [49]. Although exact incidence of AKI in PALF is unknown, the prospective PALF study reported the need for hemofiltration in nearly $10 \%$ of patients [3]. AKI has been reported in 15-20\% of children with ALF where it was associated with decreased survival [50].

AKI in ALF can be multifactorial, and causes include hypovolemia, sepsis, acute tubular necrosis, nephrotoxic medications, acetaminopheninduced renal injury, and functional renal failure [51, 52]. Functional renal failure can arise from a mechanism similar to hepatorenal syndrome in chronic liver disease. Intrarenal vasoconstriction leads to decreased renal perfusion and subsequent kidney injury [51-53].

Assessment of renal dysfunction in children with ALF may be augmented by using multiple criteria such as the combination of serum creatinine $(\mathrm{sCr})$, urinary output, and fluid balance aid in diagnosing AKI. SCr by itself may overestimate renal function, and change of $\mathrm{SCr}$ over baseline is more relevant over a single value to assess progression of renal injury $[54,55]$. Urinary biomarkers like neutrophil gelatinase-associated lipocalin, IL-18, kidney injury molecule-1, and livertype fatty acid-binding protein are emerging for evaluation of pediatric AKI; however, these have not been studied in PALF [56].

Management of AKI in PALF should be focused on interventions to reduce kidney injury and prevent progression to renal failure. Adequate hydration, avoiding excessive diuresis, maintaining adequate renal perfusion pressure, and minimizing the use or adjusting the dose of intravenous contrast and nephrotoxic medications are some measures to prevent AKI in ALF [16, 17, 52]. Intravenous fluid challenge should be considered in patients with suspected prerenal azotemia, but volume overload should be avoided in patients with PALF [4].

The criteria for initiation or discontinuation of RRT in PALF are ill-defined due to lack of suffi- cient data. RRT (hemofiltration or dialysis) can help correct electrolyte imbalances, worsening acidosis, fluid overload, and hyperammonemia. The degree of kidney injury, electrolyte disturbance, and fluid imbalance should be integrated into the decision to start RRT in patients with PALF [4]. Continuous renal replacement therapy is preferred over intermittent hemodialysis due to lower risk of hemodynamic instability and worsening ICP $[17,55]$. In a recent study on a large cohort of patients enrolled in ALFSG, serum ammonia modulation with CRRT improved 21-day transplant-free survival [21]. Although there is inadequate data in PALF regarding use of CRRT in management of HE, early use of CRRT should be considered in patients at a greater risk of progression of HE (e.g., high-grade encephalopathy, advanced AKI, vasopressors, etc.).

AKI in PALF resolves after restoration of liver function in majority of cases. However, in certain circumstances, simultaneous liver and kidney transplantation must be considered. In adults, indications for concurrent liver/kidney transplantations are based on degree and duration of renal injury and are strongly considered if patient has needed dialysis for 8-12 weeks [57]. However, there is minimal data, mainly based on singlecenter experience, available for guidance regarding liver/kidney transplant in children [58].

\section{Fluid, Electrolytes, and Nutrition}

Acid-base imbalances, electrolyte abnormalities, and metabolic derangements are common in PALF and need to be identified and corrected fastidiously due to their life-threatening potential. Serum electrolytes should be monitored frequently and corrected meticulously to prevent mortality and decrease morbidity in these critically ill patients. Alkalosis and acidosis both may occur in ALF and should be managed by correcting the cause of acid-base imbalance [17]. Hyponatremia and hypokalemia can be secondary to ascites, dilution from aggressive volume resuscitation, and urinary losses from diuretic use. Hyponatremia should be strictly avoided as it can exacerbate cerebral edema. 
Hypophosphatemia, hypocalcemia, and hypomagnesemia are commonly observed, can be profound, and should be corrected.

ALF is a catabolic state with negative nitrogen balance due to decreased oral intake and increased energy expenditure. Caloric requirements in these patients increase by about $20 \%$ [59]. There is some data to guide nutrition in children with chronic liver disease and cirrhosis which can be extrapolated to PALF in the absence of studies to guide nutritional support in PALF [59]. Nutrition in PALF should be aimed at providing adequate calories to meet the metabolic needs, enough glucose to maintain euglycemia, and appropriate amounts of protein to overcome negative nitrogen balance without worsening hyperammonemia [60]. In general, enteral feeds should be used when possible. Formula with high caloric density should be preferred to avoid excess free water administration [16]. Parenteral nutrition is safe in PALF and can be used as a second-line option to provide adequate nutrition in patients who cannot tolerate enteral feedings [60]. When using parenteral nutrition, intravenous lipids can be used as a source of nutrition; however, they should be avoided in patients with some disorders such as mitochondrial diseases due to the concern for abnormal fat metabolism [61]. Glucose infusion rates as high as $10-15 \mathrm{mg} / \mathrm{kg} / \mathrm{min}$ may be required to maintain euglycemia in patients with ALF [4]. Children with ALF have dysregulated homeostatic responses to hypoglycemia, and signs of hypoglycemia may be obscured in the patients with HE. Even though tight glycemic control is promoted for critically ill patients in certain ICUs across the nation, a significant risk can be created with such aggressive interventions in children with PALF and should be avoided [4, $16,17]$.

\section{Hematology-Coagulopathy}

In a recent study on 1770 adults with ALF enrolled in ALFSG, spontaneous or post-procedural bleeding was deemed as a proximate cause of death in less than $5 \%$ of patients, half of whom had bled after the placement of an ICP monitor
[62]. Overall incidence of bleeding was about $10 \%$ with spontaneous upper gastrointestinal bleed being the most common location in ALF. Although elevated INR with or without encephalopathy is a universal requirement for diagnosing a patient with ALF, INR is not a good predictor of risk of bleeding. Elevation in INR is due to decrease in both pro- and anticoagulant factors, and it reflects the synthetic dysfunction of the liver more precisely than the risk of bleeding in ALF. In the abovementioned study, a low platelet count, severity of systemic complications, and SIRS were found to be more important risk factors for bleeding than INR [62]. Platelet count as well as some less commonly used coagulation tests like thromboelastography may be better in assessing the severity of bleeding diathesis $[63,64]$ as well as guiding potential interventions.

Administration of vitamin $\mathrm{K}$ is recommended as vitamin $\mathrm{K}$ deficiency has been reported in adults with ALF [65]. Prophylactic administration of plasma to correct INR may be deleterious not only due to associated adverse effects of volume overload, transfusion-related lung injury, and immune dysregulation but also due to its potential to exacerbate a preexisting hypercoagulable state leading to microvascular thrombosis worsening the primary hepatic injury [62]. However, plasma transfusion can be used prior to invasive procedures or in the setting of active bleeding [17]. In patients with ALF at risk of volume overload due to renal injury, recombinant factor VIIa (rFVIIa) can be used to facilitate invasive procedures; however, these must be used with caution as systemic venous thrombosis has been reported with its use $[66,67]$. Platelet transfusions are advised if platelets $<10,000$ or $<50,000$ with evidence of overt bleeding or need for invasive procedure. However, platelet transfusion is not recommended for platelet count $>50,000[16,17]$.

\section{Gastrointestinal}

Clinically significant bleeding is rare despite the degree of elevation of INR [68]. Gastrointestinal 
bleeding in patients with ALF is mainly stress induced or acid related. The AASLD guidelines on management of ALF recommend $\mathrm{H} 2$ blockers or proton pump inhibitors (PPI) for prophylactic prevention of this type of GI bleeding [17]. Variceal bleeding is rare in patients with ALF. Ascites may develop in a minority of patients with ALF, and spironolactone is the drug of choice to manage ascites of hepatic origin. Diuresis is indicated only if there is respiratory compromise or significant discomfort due to abdominal distension. Aggressive diuresis should be avoided to prevent precipitation of hepatorenal syndrome [5].

\section{Infection: SIRS}

The liver is involved in multiple immune-related functions which are disturbed in ALF making these patients more susceptible to infection. Additionally, these patients have defects in many other host defense mechanism pathways which decrease their ability to fight against infections. As a result, infection and systemic inflammatory response syndrome contribute to significant morbidity and mortality in these patients. Bacterial infections account for 10-37\% of mortality in adults with ALF [69, 70]. In a retrospective review, the incidence of bacterial infection in children with PALF was about $25 \%$, and bacterial infections were associated with increased morbidity in these patients [71]. Systemic inflammatory response syndrome (SIRS) has been reported in $50-60 \%$ of adults with ALF [69]. Increased SIRS components are directly correlated to increasing mortality and are strongly associated with worsening encephalopathy. Encephalopathy has been shown to progress in majority of patients with infection and in 50\% of patients with greater than two SIRS components versus $25 \%$ of patients without SIRS [72]. There are no retrospective or prospective studies to assess the association or incidence of infection or SIRS with outcomes in PALF.

In spite of several studies examining the use of prophylactic antibiotics in management of ALF, the results remain inconclusive. There are no clear guidelines for the use of prophylactic antibiotics or antifungals for liver failure in adults or children, and these should be avoided $[16,17]$. Pulmonary, urinary, and blood stream infections are the most common sites for bacterial infection, and gram-positive cocci like staphylococci and streptococci and enteric gramnegative bacilli are the most commonly isolated organisms [66]. Obtaining appropriate evaluations in patients with ALF and signs/symptoms of infection should not be delayed. This may include chest X-ray and urine and blood cultures with any suspicion of infection, SIRS, refractory hypotension, or worsening encephalopathy [16, 17]. Empiric antibiotics should be initiated in patients exhibiting SIRS and should have adequate coverage for the abovementioned bacterial infections.

\section{Liver Support Systems}

In acute liver failure, CRRT is highly effective in the removal of smaller molecules of water-soluble toxins, i.e., urea, ammonia, etc. However, the larger or albumin-bound non-water-soluble molecules like cytokines, bile acids, bilirubin, and metabolites of aromatic amino acids and medium chain fatty acids are not successfully removed during hemodialysis. These large albumin-bound non-soluble molecules accumulate and contribute to progression of liver failure [73, 74]. Highvolume hemofiltration has been used to remove circulatory cytokines and was associated with improved hemodynamics and encephalopathy [75]. In a randomized control trial in adults with ALF, high-volume nonselective plasmapheresis demonstrated improved transplant-free survival when compared to a control group along with decreased SIRS score and SOFA score [76]. High-volume plasmapheresis dampened innate immune response, and early use of plasmapheresis might provide a window of homeostasis for the liver to regenerate [76]. However, a small retrospective pediatric study failed to show survival benefit with the use of plasma exchange [77]. 


\section{Artificial Support Systems}

Artificial and bioartificial systems have been devised to help detoxify the plasma or blood and support the patient either until the native liver recovers or as a bridge to transplant. The artificial support systems use series of filters to provide detoxification support. These sorbent-based systems use adherent particles in an extracorporeal circuit to help detoxify the blood from various cytokines which indirectly help improve the biochemical and clinical parameters in patients. Molecular adsorbent recirculating system (MARS) and Prometheus are the two commercially available liver support systems. These have been successfully used in adults with ALF to improve biochemical parameters like ammonia as well as HE [78]. However, a recent RCT failed to demonstrate any survival benefit with the use of MARS in patients with liver failure [79]. A recent pediatric case series on use of MARS in 20 patients with PALF reported significant improvement in serum ammonia, bilirubin, bile acids, and creatinine levels but without any survival benefit [80].

\section{Bioartificial Support Systems}

The bioartificial or biologic systems use cellular material which, in theory, not only provide detoxification but have the potential to mimic synthetic functions of the hepatocytes. These types of support systems use hepatocytes, human or nonhuman in origin, with or without concurrent use of other sorbents. Five such systems are currently being clinically tested. These include HepatAssist $^{\mathrm{TM}}$, extracorporeal liver support device $\left(\right.$ ELAD $\left.^{\mathrm{TM}}\right)$, modular extracorporeal liver support system (MELSTM), bioartificial liver support system (BLSS ${ }^{\mathrm{TM}}$ ), and Amsterdam Medical Center bioartificial liver (AMC-BAL ${ }^{\mathrm{TM}}$ ). A randomized control trial assessing the role of bioartificial liver support system did not demonstrate any benefit in survival between treatment and control group [81].

The limited studies evaluating the role of artificial and bioartificial liver support systems have demonstrated improvements in biochemical profile but have limited clinical and survival benefits. Plasma exchange may improve survival; however, further studies are needed to justify its use in PALF. Based on lack of convincing survival benefit in adult studies and paucity of data in PALF, liver support systems are not currently advocated in children with liver failure [82].

\section{Liver Transplantation}

Liver transplantation is a lifesaving intervention in patients who fail to show signs of spontaneous recovery with supportive care and have otherwise guarded prognosis. Timely transplantation is critical to minimize posttransplant morbidity and improve survival in these patients. About $10 \%$ of pediatric liver transplants in the USA are performed on children with PALF [6]. Uncontrolled sepsis, certain mitochondrial disorders, and cerebral edema with uncal herniation are contraindications for liver transplant, and the AASLD guidelines for evaluation of a pediatric patient for liver transplantation recommend identifying underlying etiology for PALF to recognize treatable etiologies (Table 9.4) as well as contraindications for liver transplant [83].

Liver transplantation for ALF has been associated with inferior outcomes than liver transplantation for chronic liver diseases [84]. In the SPLIT database, factors predicting worse outcomes were age $<1$ year, advanced/grade $4 \mathrm{HE}$, and need for dialysis prior to transplantation [84]. In a recent single-center outcome report on 122 PALF patients who underwent liver transplantation, 1-year, 5-year, and 10-year survival rates were $81 \%, 77 \%$, and $73 \%$, respectively [85]. In the same study, low creatinine clearance and less than 7 days between onset or jaundice and encephalopathy were associated with poor patient survival. Age less than 2 years, low creatinine clearance, and PELD/MELD score greater than 25 were associated with increased graft loss [85]. 
Table 9.4 Etiology specific treatment $[4,5]$

\begin{tabular}{|c|c|c|}
\hline Etiology & Diagnosis & Treatment \\
\hline \multicolumn{3}{|l|}{ Infections } \\
\hline Hepatitis B & $\begin{array}{l}\text { Hepatitis B PCR, hepatitis B surface or e } \\
\text { antigen }\end{array}$ & Lamivudine, tenofovir, entecavir \\
\hline HSV 1,2 & $\begin{array}{l}\text { Viral PCR, viral culture from vesicles, } \\
\text { oropharynx, conjunctiva, blood, and CSF }\end{array}$ & IV acyclovir \\
\hline Enterovirus & Viral PCR & Pleconaril - possibly helpful \\
\hline Parvovirus & Viral PCR & $\begin{array}{l}\text { IV immunoglobulin - possibly } \\
\text { helpful }\end{array}$ \\
\hline \multicolumn{3}{|l|}{ Metabolic } \\
\hline Galactosemia & $\begin{array}{l}\text { Elevated urine non-glucose-reducing } \\
\text { substances, galactose-1 phosphatase uridyl } \\
\text { transferase enzyme assay }\end{array}$ & Switch to lactose-free formula \\
\hline Tyrosinemia type 1 & $\begin{array}{l}\text { Markedly elevated AFP, elevated urine } \\
\text { succinylacetone, enzyme assay or genetic } \\
\text { testing for fumarylacetoacetate hydrolase }\end{array}$ & PO NTBC \\
\hline Wilson's disease & $\begin{array}{l}\text { Low serum ceruloplasmin, high } 24 \text {-h urine } \\
\text { copper, high liver copper, presence of } \\
\text { Kayser-Fleischer rings (in approximately } 50 \% \\
\text { patients) }\end{array}$ & $\begin{array}{l}\text { Copper chelation with agents like } \\
\text { D-penicillamine, trientene, zinc, } \\
\text { etc.; sometimes plasmapheresis } \\
\text { may be needed }\end{array}$ \\
\hline \multicolumn{3}{|l|}{ Immune dysregulation } \\
\hline Autoimmune hepatitis & $\begin{array}{l}\text { Autoimmune hepatitis serology (see } \\
\text { Table 9.1); elevated Ig G levels }\end{array}$ & $\begin{array}{l}\text { IV methylprednisolone while } \\
\text { concomitant evaluation for LT }\end{array}$ \\
\hline $\begin{array}{l}\text { Gestational alloimmune } \\
\text { liver disease (GALD)/ } \\
\text { neonatal hemochromatosis }\end{array}$ & $\begin{array}{l}\text { High serum ferritin; lip/salivary gland biopsy; } \\
\text { characteristic features on MRI brain/liver/ } \\
\text { pancreas }\end{array}$ & $\begin{array}{l}\text { High-dose IV immunoglobulin; } \\
\text { can also be given prophylactic } \\
\text { during pregnancy } \\
\text { May need exchange transfusion }\end{array}$ \\
\hline $\begin{array}{l}\text { Hemophagocytic } \\
\text { lymphohistiocytosis (HLH) }\end{array}$ & $\begin{array}{l}\text { Cytopenias, high serum triglyceride and } \\
\text { ferritin, low fibrinogen; high soluble IL-2 } \\
\text { receptor, low or absent NK cell activity; } \\
\text { genetic testing and/or bone marrow biopsy } \\
\text { proved to be diagnostic }\end{array}$ & $\begin{array}{l}\text { High-dose corticosteroids, } \\
\text { chemotherapy and/or bone } \\
\text { marrow transplantation }\end{array}$ \\
\hline \multicolumn{3}{|l|}{ Drugs/exposures } \\
\hline Acetaminophen & $\begin{array}{l}\text { History suggestive or suspicious of ingestion; } \\
\text { elevated acetaminophen level } 4 \mathrm{~h} \text { after } \\
\text { ingestion }\end{array}$ & $\begin{array}{l}\text { NAC should be started as soon as } \\
\text { possible in all patients where } \\
\text { acetaminophen overdose is } \\
\text { suspected. }\end{array}$ \\
\hline Amanita toxicity & $\begin{array}{l}\text { History of Amanita phalloides and Amanita } \\
\text { virosa ingestion }\end{array}$ & PO or IV silibinin \\
\hline \multicolumn{3}{|l|}{ Others } \\
\hline Budd-Chiari syndrome & $\begin{array}{l}\text { Finding of hepatic vein thrombosis on imaging } \\
\text { studies }\end{array}$ & $\begin{array}{l}\text { TIPS - if possible; LT might still } \\
\text { be necessary }\end{array}$ \\
\hline
\end{tabular}

$A F P$ alpha-fetoprotein, $L T$ liver transplantation, NTBC 2-(2-nitro-4-trifluoro-methyl-benzoyl)-1,3-cyclohexadion, $I L$ interleukin, $N K$ cell natural killer cell

\section{Prognosis}

There are several prognostic scoring systems available; however, none of these have been able to well-define the indications for liver transplantation. The King's College Hospital Criteria (KCHC), the Model for End-Stage Liver Disease
(MELD) score, and the Sequential Organ Failure Assessment (SOFA) score are among the few most frequently used prognostic scoring systems in adults. However, none of these adequately predict outcome or candidacy for transplantation, and the AASLD guidelines for management of acute liver failure recommend against using these 
for organ allocation [17]. Prognostic scoring systems for PALF are poorly defined and not adequately validated. The $\mathrm{KCHC}$ has been extensively used in adult ALF; however, when the PALF study group tried to validate the criteria for use in non-acetaminophen-induced PALF patients, it did not reliably predict chance of survival in PALF, and its sensitivity and positive predictive value were significantly lower than the original study [86]. Serum albumin level, serum bilirubin level, PT-INR, age, and weight have been used in the Pediatric End-Stage Liver Disease (PELD) score to predict mortality in children with chronic liver disease [87]. This scoring system has not been validated for use in PALF. The pediatric liver injury unit (LIU) score is an upcoming dynamic scoring system, which incorporates the use of peak values of total bilirubin and PT-INR during hospitalization to stratify patients into low, medium, or high risk of mortality. It may prove to be a beneficial tool for prediction of outcomes in PALF and thus the need for liver transplantation [88, 89]. Currently, we do not have a single universal scoring system to help reliably predict mortality and need for transplantation, thus streamlining the process of listing and organ allocation in PALF.

\section{Outcomes}

Before liver transplantation was adopted as a lifesaving modality for management of acute liver failure, the overall survival rate for children with PALF was less than $50 \%$ and was even worse (less than 10\%) for patients with advances stages of encephalopathy. However, more recent data has been promising. In a recent analysis of 348 patients with PALF, 94\% of children with acetaminophen-induced liver failure survived [3]. Patients with PALF who did not have an underlying etiology identified had the worst outcome with more than $50 \%$ mortality [3]. Patients who never had HE were more likely to recover spontaneously. Total bilirubin $\geq 5 \mathrm{mg} / \mathrm{dl}$, INR $\geq 2.55$, and presence of HE, were identified as risk factors to predict death or need for liver transplantation.

\section{Conclusion}

Despite the improvement in supportive care and outcomes in PALF in last few decades, critical care management remains poorly defined and guided mainly by adult data and guidelines. This makes PALF one of the most challenging conditions to manage. Intense supportive care, thorough diagnostic evaluation, and early detection with prompt treatment of complications help improve outcomes. Improved availability of organs for transplant, better prognostic system, and effective liver support systems are highly needed to improve survival and decrease the uncertainty associated with this devastating disease.

\section{References}

1. Wlodzimirow KA, Eslami S, Abu-Hanna A, Nieuwoudt M, Chamuleau RA. Systematic review: acute liver failure - one disease, more than 40 definitions. Aliment Pharmacol Ther. 2012;35(11):1245-56. https://doi. org/10.1111/j.1365-2036.2012.05097.x.

2. Rivera-Penera T, Moreno J, Skaff C, McDiarmid S, Vargas J, Ament ME. Delayed encephalopathy in fulminant hepatic failure in the pediatric population and the role of liver transplantation. J Pediatr Gastroenterol Nutr. 1997;24(2):128-34.

3. Squires RH Jr, Shneider BL, Bucuvalas J, Alonso E, Sokol RJ, Narkewicz MR, et al. Acute liver failure in children: the first 348 patients in the pediatric acute liver failure study group. J Pediatr. 2006;148(5):6528. https://doi.org/10.1016/j.jpeds.2005.12.051.

4. Lutfi R, Abulebda K, Nitu ME, Molleston JP, Bozic MA, Subbarao G. Intensive Care Management of Pediatric Acute Liver Failure. J Pediatr Gastroenterol Nutr. 2017;64(5):660-70. https://doi. org/10.1097/mpg.0000000000001441.

5. Squires RH Jr. Acute liver failure in children. Semin Liver Dis. 2008;28(2):153-66. https://doi.org/10.105 5/s-2008-1073115.

6. Kim WR, Lake JR, Smith JM, Skeans MA, Schladt DP, Edwards EB, et al. OPTN/SRTR 2015 annual data report: liver. Am J Transplant. 2017;17:174-251. https://doi.org/10.1111/ajt.14126.

7. Sundaram SS, Alonso EM, Narkewicz MR, Zhang $\mathrm{S}$, Squires RH. Characterization and outcomes of young infants with acute liver failure. J Pediatr. 2011;159(5):813-818.e1. https://doi.org/10.1016/j. jpeds.2011.04.016.

8. Narkewicz MR, Dell Olio D, Karpen SJ, Murray KF, Schwarz K, Yazigi N, et al. Pattern of diagnostic evaluation for the causes of pediatric acute liver failure: 
an opportunity for quality improvement. J Pediatr. 2009;155(6):801-6.e1. https://doi.org/10.1016/j. jpeds.2009.06.005.

9. Bhatt H, Rao GS. Management of Acute Liver Failure: a pediatric perspective. Curr Pediatr Rep. 2018; https://doi.org/10.1007/s40124-018-0174-7.

10. Singhal A, Vadlamudi S, Stokes K, Cassidy FP, Corn A, Shrago SS, et al. Liver histology as predictor of outcome in patients with acute liver failure. Transpl Int. 2012;25(6):658-62. https://doi. org/10.1111/j.1432-2277.2012.01470.x.

11. Miraglia R, Luca A, Gruttadauria S, Minervini MI, Vizzini G, Arcadipane A, et al. Contribution of transjugular liver biopsy in patients with the clinical presentation of acute liver failure. Cardiovasc Intervent Radiol. 2006;29(6):1008-10. https://doi.org/10.1007/ s00270-006-0052-5.

12. Ostapowicz G, Fontana RJ, Schiodt FV, Larson A, Davern TJ, Han SH, et al. Results of a prospective study of acute liver failure at 17 tertiary care centers in the United States. Ann Intern Med. 2002;137(12):947-54.

13. Scott TR, Kronsten VT, Hughes RD, Shawcross DL. Pathophysiology of cerebral oedema in acute liver failure. World J Gastroenterol. 2013;19(48):9240-55. https://doi.org/10.3748/wjg.v19.i48.9240.

14. Bernal W, Hall C, Karvellas CJ, Auzinger G, Sizer E, Wendon J. Arterial ammonia and clinical risk factors for encephalopathy and intracranial hypertension in acute liver failure. Hepatology. 2007;46(6):1844-52. https://doi.org/10.1002/hep.21838.

15. Butterworth RF. The concept of "the inflamed brain" in acute liver failure: mechanisms and new therapeutic opportunities. Metab Brain Dis. 2016;31(6):12837. https://doi.org/10.1007/s11011-015-9747-0.

16. Stravitz RT, Kramer AH, Davern T, Shaikh AO, Caldwell SH, Mehta RL, et al. Intensive care of patients with acute liver failure: recommendations of the U.S. acute liver failure study group. Crit Care Med. 2007;35(11):2498-508. https://doi. org/10.1097/01.ccm.0000287592.94554.5f.

17. Lee WM, Larson AM, Stravitz RT. AASLD position paper: the management of acute liver failure: update 2011. AASLD September. 2011.

18. Kodali S, McGuire BM. Diagnosis and Management of Hepatic Encephalopathy in fulminant hepatic failure. Clin Liver Dis. 2015;19(3):565-76. https://doi. org/10.1016/j.cld.2015.04.006.

19. Alba L, Hay JE, Angulo P, Lee WM. Lactulose therapy in acute liver failure. J Hepatol. 2002;36:33. https://doi.org/10.1016/S0168-8278(02)80097-6.

20. Stravitz RT, Gottfried M, Durkalski V, Fontana RJ, Hanje AJ, Koch D, et al. Safety, tolerability and pharmacokinetics of L-ornithine Phenylacetate in patients with acute liver injury/failure and Hyperammonemia. Hepatology. 2017; https://doi.org/10.1002/ hep. 29621

21. Cardoso FS, Gottfried M, Tujios S, Olson JC, Karvellas CJ. Continuous renal replacement therapy is associated with reduced serum ammonia levels and mortality in acute liver failure. Hepatology. 2017; https://doi.org/10.1002/hep.29488.

22. Bucuvalas J, Yazigi N, Squires RH Jr. Acute liver failure in children. Clin Liver Dis. 2006;10(1):149-68., vii. https://doi.org/10.1016/j.cld.2005.10.006.

23. Vaquero J, Fontana RJ, Larson AM, Bass NM, Davern TJ, Shakil AO, et al. Complications and use of intracranial pressure monitoring in patients with acute liver failure and severe encephalopathy. Liver Transpl. 2005;11(12):1581-9. https://doi.org/10.1002/ 1t.20625.

24. Rajajee V, Fontana RJ, Courey AJ, Patil PG. Protocol based invasive intracranial pressure monitoring in acute liver failure: feasibility, safety and impact on management. Crit Care. 2017;21(1):178. https://doi. org/10.1186/s13054-017-1762-6.

25. Kamat P, Kunde S, Vos M, Vats A, Gupta N, Heffron $\mathrm{T}$, et al. Invasive intracranial pressure monitoring is a useful adjunct in the management of severe hepatic encephalopathy associated with pediatric acute liver failure. Pediatr Crit Care Med. 2012;13(1):e33-8. https://doi.org/10.1097/PCC.0b013e31820ac08f.

26. Richardson D, Bellamy M. Intracranial hypertension in acute liver failure. Nephrol Dial Transplant. 2002;17(1):23-7.

27. Murphy N, Auzinger G, Bernel W, Wendon J. The effect of hypertonic sodium chloride on intracranial pressure in patients with acute liver failure. Hepatology. 2004;39(2):464-70. https://doi. org/10.1002/hep.20056.

28. Bell MJ, Kochanek PM. Pediatric traumatic brain injury in 2012: the year with new guidelines and common data elements. Crit Care Clin. 2013;29(2):22338. https://doi.org/10.1016/j.ccc.2012.11.004.

29. Kochanek PM, Carney N, Adelson PD, Ashwal $\mathrm{S}$, Bell MJ, Bratton S, et al. Guidelines for the acute medical management of severe traumatic brain injury in infants, children, and adolescents-second edition. Pediatr Crit Care Med. 2012;13(Suppl 1):S1-82. https://doi.org/10.1097/ PCC.0b013e31823f435c.

30. Ede RJ, Gimson AES, Bihari D, Williams $\mathrm{R}$. Controlled hyperventilation in the prevention of cerebral oedema in fulminant hepatic failure. J Hepatol. 1986;2(1):43-51. https://doi.org/10.1016/ S0168-8278(86)80007-1.

31. Vaquero J. Therapeutic hypothermia in the management of acute liver failure. Neurochem Int. 2012;60(7):723-35. https://doi.org/10.1016/j. neuint.2011.09.006

32. Stravitz RT, Larsen FS. Therapeutic hypothermia for acute liver failure. Crit Care Med. 2009;37(7 Suppl):S258-64. https://doi.org/10.1097/ CCM.0b013e3181aa5fb8.

33. Karvellas CJ, Cavazos J, Battenhouse H, Durkalski V, Balko J, Sanders C, et al. Effects of antimicrobial prophylaxis and blood stream infections in patients with acute liver failure: a retrospective cohort study. Clin Gastroenterol Hepatol. 2014;12(11):1942-9.e1. https://doi.org/10.1016/j.cgh.2014.03.011. 
34. Hussain E, Grimason M, Goldstein J, Smith CM, Alonso E, Whitington PF, et al. EEG abnormalities are associated with increased risk of transplant or poor outcome in children with acute liver failure. J Pediatr Gastroenterol Nutr. 2014;58(4):449-56. https://doi. org/10.1097/mpg.0000000000000271.

35. Ellis AJ, Wendon JA, Williams R. Subclinical seizure activity and prophylactic phenytoin infusion in acute liver failure: a controlled clinical trial. Hepatology. 2000;32(3):536-41. https://doi.org/10.1053/ jhep.2000.9775.

36. Aggarwal S, Brooks DM, Kang Y, Linden PK, Patzer JF 2nd. Noninvasive monitoring of cerebral perfusion pressure in patients with acute liver failure using transcranial doppler ultrasonography. Liver Transpl. 2008;14(7):1048-57. https://doi.org/10.1002/ 1t. 21499 .

37. Bhatia V, Batra Y, Acharya SK. Prophylactic phenytoin does not improve cerebral edema or survival in acute liver failure-a controlled clinical trial. J Hepatol. 2004;41(1):89-96. https://doi.org/10.1016/j. jhep.2004.03.017.

38. Basile AS, Hughes RD, Harrison PM, Murata Y, Pannell L, Jones EA, et al. Elevated brain concentrations of 1,4-benzodiazepines in fulminant hepatic failure. N Engl J Med. 1991;325(7):473-8. https:// doi.org/10.1056/nejm199108153250705.

39. Wijdicks EF, Nyberg SL. Propofol to control intracranial pressure in fulminant hepatic failure. Transplant Proc. 2002;34(4):1220-2.

40. Cunningham FE, Baughman VL, Tonkovich L, Lam N, Layden T. Pharmacokinetics of Dexmedetomidine (DEX) in patients with hepatic failure (HF). Clin Pharmacol Ther. 1999;65(2):128. https://doi. org/10.1016/S0009-9236(99)80045-9.

41. Craig RG, Hunter JM. Neuromuscular blocking drugs and their antagonists in patients with organ disease. Anaesthesia. 2009;64(Suppl 1):55-65. https://doi. org/10.1111/j.1365-2044.2008.05871.x.

42. Annane D, Sebille V, Charpentier C, Bollaert PE, Francois B, Korach JM, et al. Effect of treatment with low doses of hydrocortisone and fludrocortisone on mortality in patients with septic shock. JAMA. 2002;288(7):862-71.

43. Marik PE, Gayowski T, Starzl TE. The hepatoadrenal syndrome: a common yet unrecognized clinical condition. Crit Care Med. 2005;33(6):1254-9.

44. Annane D, Bellissant E, Sebille V, Lesieur O, Mathieu B, Raphael JC, et al. Impaired pressor sensitivity to noradrenaline in septic shock patients with and without impaired adrenal function reserve. $\mathrm{Br} \mathrm{J}$ Clin Pharmacol. 1998;46(6):589-97.

45. Soltys KA, Mazariegos GV. Hepatoadrenal syndrome in critically ill children with liver failure: is it true, true, and unrelated? Pediatr Crit Care Med. 2012;13(3):366-7. https://doi.org/10.1097/ PCC.0b013e318238b286.

46. Hauser GJ, Brotzman HM, Kaufman SS. Hepatoadrenal syndrome in pediatric patients with end-stage liver disease. Pediatr Crit Care
Med. 2012;13(3):e145-9. https://doi.org/10.1097/ PCC.0b013e31822f1b9e.

47. Audimoolam VK, McPhail MJ, Wendon JA, Willars C, Bernal W, Desai SR, et al. Lung injury and its prognostic significance in acute liver failure. Crit Care Med. 2014;42(3):592-600. https://doi. org/10.1097/01.ccm.0000435666.15070.d5.

48. Khemani RG, Smith LS, Zimmerman JJ, Erickson S. Pediatric acute respiratory distress syndrome: definition, incidence, and epidemiology: proceedings from the pediatric acute lung injury consensus conference. Pediatr Crit Care Med. 2015;16(5 Suppl 1):S23-40. https://doi.org/10.1097/ pcc.0000000000000432.

49. Tujios SR, Hynan LS, Vazquez MA, Larson AM, Seremba E, Sanders CM, et al. Risk factors and outcomes of acute kidney injury in patients with acute liver failure. Clin Gastroenterol Hepatol. 2015;13(2):3529. https://doi.org/10.1016/j.cgh.2014.07.011.

50. Kulkarni S, Perez C, Pichardo C, Castillo L, Gagnon $\mathrm{M}$, Beck-Sague C, et al. Use of pediatric health information system database to study the trends in the incidence, management, etiology, and outcomes due to pediatric acute liver failure in the United States from 2008 to 2013. Pediatr Transplant. 2015;19(8):888-95. https://doi.org/10.1111/petr.12596.

51. Moore JK, Love E, Craig DG, Hayes PC, Simpson KJ. Acute kidney injury in acute liver failure: a review. Expert Rev Gastroenterol Hepatol. 2013;7(8):701-12. https://doi.org/10.1586/17474124.2013.837264.

52. Leventhal TM, Liu KD. What a nephrologist needs to know about acute liver failure. Adv Chronic Kidney Dis. 2015;22(5):376-81. https://doi.org/10.1053/j. ackd.2015.06.006.

53. Angeli P, Gines P, Wong F, Bernardi M, Boyer TD, Gerbes A, et al. Diagnosis and management of acute kidney injury in patients with cirrhosis: revised consensus recommendations of the International Club of Ascites. J Hepatol. 2015;62(4):968-74. https://doi. org/10.1016/j.jhep.2014.12.029.

54. Fortenberry JD, Paden ML, Goldstein SL. Acute kidney injury in children: an update on diagnosis and treatment. Pediatr Clin N Am. 2013;60(3):669-88. https://doi.org/10.1016/j.pcl.2013.02.006.

55. Davenport A. Continuous renal replacement therapy for liver disease. Hemodial Int. 2003;7(4):348-52. https://doi.org/10.1046/j.1492-7535.2003.00061.x.

56. Devarajan P. Emerging urinary biomarkers in the diagnosis of acute kidney injury. Expert Opin Med Diagn. 2008;2(4):387-98. https://doi. org/10.1517/17530059.2.4.387.

57. Nadim MK, Sung RS, Davis CL, Andreoni KA, Biggins SW, Danovitch GM, et al. Simultaneous liverkidney transplantation summit: current state and future directions. Am J Transplant. 2012;12(11):2901-8. https://doi.org/10.1111/j.1600-6143.2012.04190.x.

58. Jalanko H, Pakarinen M. Combined liver and kidney transplantation in children. Pediatr Nephrol. 2014;29(5):805-14.; quiz 12. https://doi.org/10.1007/ s00467-013-2487-7. 
59. Plauth M, Cabre E, Riggio O, Assis-Camilo M, Pirlich M, Kondrup J, et al. ESPEN guidelines on enteral nutrition: liver disease. Clin Nutr. 2006;25(2):285-94. https://doi.org/10.1016/j.clnu.2006.01.018.

60. Plauth M, Cabre E, Campillo B, Kondrup J, Marchesini G, Schutz T, et al. ESPEN guidelines on parenteral nutrition: hepatology. Clin Nutr. 2009;28(4):436-44. https://doi.org/10.1016/j.clnu.2009.04.019.

61. Schutz T, Bechstein WO, Neuhaus P, Lochs H, Plauth M. Clinical practice of nutrition in acute liver failure-a European survey. Clin Nutr. 2004;23(5):97582. https://doi.org/10.1016/j.clnu.2004.03.005.

62. Stravitz RT, Ellerbe C, Durkalski V, Schilsky M, Fontana RJ, Peterseim C, et al. Bleeding complications in acute liver failure. Hepatology. 2018;67(5):193142. https://doi.org/10.1002/hep.29694.

63. Stravitz RT, Lisman T, Luketic VA, Sterling RK, Puri P, Fuchs M, et al. Minimal effects of acute liver injury/acute liver failure on hemostasis as assessed by thromboelastography. J Hepatol. 2012;56(1):129-36. https://doi.org/10.1016/j.jhep.2011.04.020.

64. Agarwal B, Wright G, Gatt A, Riddell A, Vemala V, Mallett S, et al. Evaluation of coagulation abnormalities in acute liver failure. J Hepatol. 2012;57(4):7806. https://doi.org/10.1016/j.jhep.2012.06.020.

65. Pereira SP, Rowbotham D, Fitt S, Shearer MJ, Wendon J, Williams R. Pharmacokinetics and efficacy of oral versus intravenous mixed-micellar phylloquinone (vitamin K1) in severe acute liver disease. J Hepatol. 2005;42(3):365-70. jhep.2004.11.030. https://doi.org/10.1016/j.

66. Shami VM, Caldwell SH, Hespenheide EE, Arseneau KO, Bickston SJ, Macik BG. Recombinant activated factor VII for coagulopathy in fulminant hepatic failure compared with conventional therapy. Liver Transpl. 2003;9(2):138-43. https://doi.org/10.1053/ jlts.2003.50017.

67. Pavese P, Bonadona A, Beaubien J, Labrecque P, Pernod G, Letoublon C, et al. FVIIa corrects the coagulopathy of fulminant hepatic failure but may be associated with thrombosis: a report of four cases. Can J Anaesth. 2005;52(1):26-9. https://doi.org/10.1007/ bf03018576.

68. Munoz SJ, Stravitz RT, Gabriel DA. Coagulopathy of acute liver failure. Clin Liver Dis. 2009;13(1):95-107. https://doi.org/10.1016/j.cld.2008.10.001.

69. Rolando N, Wade J, Davalos M, Wendon J, PhilpottHoward J, Williams R. The systemic inflammatory response syndrome in acute liver failure. Hepatology. 2000;32(4 Pt 1):734-9. https://doi.org/10.1053/ jhep.2000.17687.

70. Rolando N, Harvey F, Brahm J, Philpott-Howard J, Alexander G, Gimson A, et al. Prospective study of bacterial infection in acute liver failure: an analysis of fifty patients. Hepatology. 1990;11(1):49-53.

71. Godbole G, Shanmugam N, Dhawan A, Verma A. Infectious complications in pediatric acute liver failure. J Pediatr Gastroenterol Nutr. 2011;53(3):320 5. https://doi.org/10.1097/MPG.0b013e318222b0cd.
72. Vaquero J, Polson J, Chung C, Helenowski I, Schiodt $\mathrm{FV}$, Reisch $\mathrm{J}$, et al. Infection and the progression of hepatic encephalopathy in acute liver failure. Gastroenterology. 2003;125(3):755-64.

73. Struecker B, Raschzok N, Sauer IM. Liver support strategies: cutting-edge technologies. Nat Rev Gastroenterol Hepatol. 2014;11(3):166-76. https:// doi.org/10.1038/nrgastro.2013.204.

74. Rademacher S, Oppert M, Jorres A. Artificial extracorporeal liver support therapy in patients with severe liver failure. Expert Rev Gastroenterol Hepatol. 2011;5(5):591-9. https://doi.org/10.1586/egh.11.59.

75. Chevret L, Durand P, Lambert J, Essouri S, Balu L, Devictor D, et al. High-volume hemofiltration in children with acute liver failure*. Pediatr Crit Care Med. 2014;15(7):e300-5. https://doi.org/10.1097/ pcc. 0000000000000172 .

76. Larsen FS, Schmidt LE, Bernsmeier C, Rasmussen A, Isoniemi H, Patel VC, et al. High-volume plasma exchange in patients with acute liver failure: an open randomised controlled trial. J Hepatol. 2016;64(1):6978. https://doi.org/10.1016/j.jhep.2015.08.018.

77. Singer AL, Olthoff KM, Kim H, Rand E, Zamir G, Shaked A. Role of plasmapheresis in the management of acute hepatic failure in children. Ann Surg. 2001;234(3):418-24.

78. Khuroo MS, Khuroo MS, Farahat KL. Molecular adsorbent recirculating system for acute and acute-onchronic liver failure: a meta-analysis. Liver Transpl. 2004;10(9):1099-106. https://doi.org/10.1002/ 1t. 20139.

79. Saliba F, Camus C, Durand F, Mathurin P, Letierce A, Delafosse B, et al. Albumin dialysis with a noncell artificial liver support device in patients with acute liver failure: a randomized, controlled trial. Ann Intern Med. 2013;159(8):522-31. https://doi. org/10.7326/0003-4819-159-8-201310150-00005.

80. Lexmond WS, Van Dael CM, Scheenstra R, Goorhuis JF, Sieders E, Verkade HJ, et al. Experience with molecular adsorbent recirculating system treatment in 20 children listed for high-urgency liver transplantation. Liver Transpl. 2015;21(3):369-80. https://doi. org/10.1002/lt.24037.

81. Demetriou AA, Brown RS Jr, Busuttil RW, Fair J, McGuire BM, Rosenthal $\mathrm{P}$, et al. Prospective, randomized, multicenter, controlled trial of a bioartificial liver in treating acute liver failure. Ann Surg. 2004;239(5):660-7. discussion 7-70

82. Jain V, Dhawan A. Extracorporeal liver support Systems in Paediatric Liver Failure. J Pediatr Gastroenterol Nutr. 2017;64(6):855-63. https://doi. org/10.1097/mpg.0000000000001500.

83. Squires RH, Ng V, Romero R, Ekong U, Hardikar W, Emre S, et al. Evaluation of the pediatric patient for liver transplantation: 2014 practice guideline by the American Association for the Study of Liver Diseases, American Society of Transplantation and the north American Society for Pediatric Gastroenterology, hepatology and 
nutrition. Hepatology. 2014;60(1):362-98. https:// doi.org/10.1002/hep.27191.

84. Baliga P, Alvarez S, Lindblad A, Zeng L. Posttransplant survival in pediatric fulminant hepatic failure: the SPLIT experience. Liver Transpl. 2004;10(11):136471. https://doi.org/10.1002/lt.20252.

85. Farmer DG, Venick RS, McDiarmid SV, Duffy JP, Kattan O, Hong JC, et al. Fulminant hepatic failure in children: superior and durable outcomes with liver transplantation over 25 years at a single center. Ann Surg. 2009;250(3):484-93. https://doi.org/10.1097/ SLA.0b013e3181b480ad.

86. Sundaram V, Shneider BL, Dhawan A, Ng VL, Im $\mathrm{K}$, Belle S, et al. King's college hospital criteria for non-acetaminophen induced acute liver failure in an international cohort of children. J Pediatr. 2013;162(2):319-23.e1. https://doi.org/10.1016/j. jpeds.2012.07.002.
87. Barshes NR, Lee TC, Udell IW, O'Mahoney CA, Karpen SJ, Carter BA, et al. The pediatric end-stage liver disease (PELD) model as a predictor of survival benefit and posttransplant survival in pediatric liver transplant recipients. Liver Transpl. 2006;12(3):47580. https://doi.org/10.1002/lt.20703.

88. Lu BR, Zhang S, Narkewicz MR, Belle SH, Squires $\mathrm{RH}$, Sokol RJ. Evaluation of the liver injury unit scoring system to predict survival in a multinational study of pediatric acute liver failure. J Pediatr. 2013;162(5):1010-6.e1-4. https://doi.org/10.1016/j. jpeds.2012.11.021.

89. Lu BR, Gralla J, Liu E, Dobyns EL, Narkewicz MR, Sokol RJ. Evaluation of a scoring system for assessing prognosis in pediatric acute liver failure. Clin Gastroenterol Hepatol. 2008;6(10):1140-5. https:// doi.org/10.1016/j.cgh.2008.05.013. 